Arq. Bras. Med. Vet. Zootec., v.70, n.3, p.905-912, 2018

\title{
Características de silagens de capim-elefante (Pennisetum purpureum) e casca de maracujá in natura
}

[Characteristics of Pennisetum purpureum and passion-fruit-peel silages]

\author{
W.B. Lira Júnior, S.B.L. Bezerra, T.A. Paula, R.N. Beelen, P.L. Amorim, P.M.G. Beelen* \\ Programa de pós-graduação - Universidade Federal de Alagoas - Rio Largo, AL
}

\section{RESUMO}

Objetivou-se avaliar as características sensoriais, as perdas totais, o padrão fermentativo e a composição bromatológica de silagens contendo combinações de capim-elefante (Pennisetum purpureum) com diferentes tempos de emurchecimento e casca de maracujá in natura $(\mathrm{CM})$. Os tratamentos experimentais foram compostos por silagens confeccionadas com 100\% de capim-elefante (CE); $100 \%$ de casca de maracujá; $75 \%$ $\mathrm{CE} / 25 \% \mathrm{CM} ; 50 \% / \mathrm{CE} 50 \% \mathrm{CM} ; 25 \% \mathrm{CE} / 75 \% \mathrm{CM}$, para cada tempo de emurchecimento do capim (zero; quatro; seis e oito horas), com três repetições. As silagens apresentaram coloração amarelada, odor levemente acre, exalando maracujá nos tratamentos contendo CM. Observou-se um aumento da perda total das silagens contendo casca de maracujá $(0,09 ; 0,15 ; 1,01 ; 1,77$ e $2,52 \mathrm{~kg}$ de perdas para os tratamentos $100 \% \mathrm{CE} ; 75 \%$ $\mathrm{CE} / 25 \% \mathrm{CM} ; 50 \% \mathrm{CE} / 50 \% \mathrm{CM} ; 25 \% \mathrm{CE} / 75 \% \mathrm{CM}$ e $100 \% \mathrm{CM}$, respectivamente). O pH e o N-NH3 variaram de 3.58 a 4.63 e de 8.11 a 12.13, respectivamente. Tratamentos com CM reduziram os teores de MS, FDN e carboidratos totais e elevaram as concentrações de PB, NIDA, NIDN e carboidratos não fibrosos das silagens avaliadas. Mesmo com baixos níveis de MS, os tratamentos proporcionaram silagens de boa qualidade.

Palavras-chave: nutrição de ruminantes, Passiflora edulis, subprodutos da fruticultura

\begin{abstract}
This study aimed at evaluating sensorial characteristics, total waste, fermentative profile, and chemical composition of Pennisetum purpureum (PP) and passion-fruit-peel (PFP) silages. Four PP dehydration times (0,4,6 and 8 hours) and five combinations of ingredients (100\% PP; 100\% PFP; $75 \%$ PP/25\% PFP; 50\% PP/50\% PFP; 25\% PP/75\% PFP) were evaluated. The silages presented a yellowish color, a slightly acrid odor, and exhaled passion fruit scent in the treatments containing PFP. There was an increase in total waste of silages containing passion fruit peel $(0.09,0.15,1.01,1.77$ and $2.52 \mathrm{~kg}$ of waste for treatments $100 \% \mathrm{PP}, 75 \%$ PP/25\% PFP, 50\% PP/50\% PFP, 25\% CE/75\% CM and 100\% CM, respectively). The pH and N-NH3 values ranged from 3.58 to 4.63 and 8.11 to 12.13, respectively. Mixtures containing PFP decreased the levels of DM and NDF and increased the levels of CP, NFC, ADIN and NDIN in the silages. Despite the reduced levels of $D M$, all treatments provided a good silage.
\end{abstract}

Keywords: ruminant nutrition, Passiflora edulis, fruit byproducts

\section{INTRODUÇ̃̃O}

Uma alternativa para o fornecimento de volumoso de qualidade em períodos de entressafra de forragem é a ensilagem de gramíneas forrageiras de bom valor nutricional, pois ela tem a vantagem de manter grande parte do valor nutritivo do material ensilado.

O capim-elefante (Pennisetum purpureum) tem se destacado entre as gramíneas forrageiras tropicais por apresentar elevada produção de

Recebido em 8 de setembro de 2016

Aceito em 3 de maio de 2017

*Autor para correspondência (corresponding author)

E-mail: patriciabeelen@gmail.com forragem por unidade de área e pelo equilíbrio nutritivo (Ferreira et al., 2010), sendo muito utilizado para a produção de silagem ou feno.

Porém, o alto teor de umidade apresentado por essa forrageira no momento ideal do corte, além do baixo teor de carboidratos solúveis e da elevada capacidade tampão, pode comprometer a qualidade da silagem (Ferreira et al., 2009). Com o intuito de minimizar as limitações do capimelefante para ensilagem, algumas técnicas têm sido testadas, como o emurchecimento do capim 
e a adição de aditivos na ensilagem. O emurchecimento consiste em deixar o capim exposto ao sol durante algumas horas antes da trituração, a fim de elevar o teor de matéria seca do capim e, assim, evitar fermentações indesejáveis.

Devido ao desenvolvimento da fruticultura no Nordeste brasileiro, a utilização dos resíduos da agroindústria do processamento de frutas (abacaxi, acerola, goiaba, manga, maracujá e melão) como aditivos vem sendo estudada, com o objetivo de melhorar nutricionalmente a qualidade das silagens de capim-elefante (Gonçalves et al., 2004; Pompeu et al., 2006; Sá et al., 2007; Ferreira et al., 2009; Ferreira et al., 2010; Bonfá et al., 2015).

As cascas são o principal componente do subproduto de maracujá, sendo importante o estudo sobre o seu valor nutritivo (Cruz et al., 2010), visando a sua utilização como aditivo ou como componente principal de silagens. Bonfá et al. (2015), ao avaliarem a adição de níveis crescentes de casca de maracujá in natura $(0,0 \%$; $12,5 \% ; 25,0 \% ; 37,5 \%$ e $50,0 \%$ ) em silagens de capim-elefante, relataram valores de $23,1 \%$ de matéria seca, 8,2\% de proteína bruta, $1,6 \%$ de carboidratos solúveis e $40,6 \%$ de fibra em detergente neutro para a casca.

O presente trabalho teve como objetivo avaliar as características sensoriais, o padrão fermentativo e a composição bromatológica de silagens contendo combinações de capim-elefante (Pennisetum purpureum) com diferentes tempos de emurchecimento e casca de maracujá in natura.

\section{MATERIAL E MÉTODOS}

O experimento foi realizado no Núcleo de Produção Animal e as análises bromatológicas foram efetuadas no laboratório de Nutrição Animal, ambos no Centro de Ciências Agrárias da Universidade Federal de Alagoas (Ceca Ufal).

O capim-elefante (Pennisetum purpureum), cultivar roxo utilizado, foi oriundo de capineira já estabelecida no setor de Forragicultura do Ceca. Foi realizado um corte de uniformização a $10 \mathrm{~cm}$ do solo e uma adubação de reposição administrada em única aplicação composta de $222,0 \mathrm{~kg}$ de ureia, $300,0 \mathrm{~kg}$ de superfosfato simples e $180,0 \mathrm{~kg}$ de cloreto de potássio por hectare na capineira, e o capim foi cortado para ensilagem 90 dias após a rebrota. O resíduo de maracujá, composto basicamente de cascas na forma in natura, foi proveniente da Cooperativa Pindorama, localizada no município de CoruripeAL.

Os tratamentos testados constaram de combinações de capim-elefante (Pennisetum purpureum) com diferentes tempos de emurchecimento e casca de maracujá in natura (CM). Foram testados os tempos de quatro, seis e oito horas de emurchecimento. Para cada tempo de emurchecimento e para a silagem de capimelefante sem emurchecimento (testemunha), foi adicionada casca de maracujá na proporção de 25; 50 e 75\%. Também foi confeccionada uma silagem com $100 \%$ de casca de maracujá.

Para a produção das silagens, foram utilizados silos de balde com capacidade de 13,7 litros, dotados de tampas com válvulas do tipo "Bunsen" e uma torneira no fundo, por onde foram diariamente escoados os efluentes.

O capim-elefante e a casca de maracujá foram triturados, com auxílio de uma picadeira, para reduzir as partículas a aproximadamente 2 a $5 \mathrm{~cm}$. Após a trituração, o material foi pesado e ensilado, com suas respectivas proporções, em uma densidade média de $750 \mathrm{~kg} / \mathrm{m}^{3}$. A compactação da massa ensilada foi feita por pisoteio e, em seguida, os silos foram fechados e as tampas lacradas com fita adesiva.

A composição bromatológica dos tratamentos no momento da ensilagem está apresentada na Tab. 1.

Os silos foram abertos com aproximadamente 45 dias de ensilagem, sendo seu conteúdo retirado e homogeneizado, descartando-se os $10 \mathrm{~cm}$ iniciais e finais.

No momento da abertura dos silos, foi feita a avaliação sensorial e retiradas amostras para análise de $\mathrm{pH}$, nitrogênio amoniacal $\left(\mathrm{N}^{\left.-\mathrm{NH}_{3}\right)}\right.$ e composição bromatológica das diferentes silagens. A avaliação sensorial foi realizada segundo metodologia descrita por Hussbaum et al. (2004), observando-se as características de cor, odor, textura e presença visível de bolores. $\mathrm{O}$ pH foi medido utilizando-se um potenciômetro 
digital, de acordo com a metodologia descrita por Silva e Queiroz (2002). O nitrogênio amoniacal foi determinado segundo Bolsen et al. (1992). As perdas totais foram calculadas pela somatória da quantificação gravimétrica dos efluentes e gases.

Tabela 1. Composição bromatológica de diferentes misturas utilizando capim-elefante e casca de maracujá, antes da ensilagem

\begin{tabular}{|c|c|c|c|c|c|c|}
\hline \multirow[b]{2}{*}{ Tratamentos } & \multicolumn{6}{|c|}{ Variáveis (\%) } \\
\hline & MS & MM & PB & FDN & FDA & LIG \\
\hline $100 \% \mathrm{CE}(0 \mathrm{~h})$ & 21,01 & 6,82 & 6,56 & 59,96 & 32,82 & 6,16 \\
\hline $75 \% \mathrm{CE} / 25 \% \mathrm{CM}(0 \mathrm{~h})$ & 18,02 & 6,58 & 6,91 & 59,60 & 32,31 & 5,08 \\
\hline $50 \% \mathrm{CE} / 50 \% \mathrm{CM}(0 \mathrm{~h})$ & 15,55 & 7,91 & 7,69 & 54,50 & 30,75 & 4,67 \\
\hline $25 \% \mathrm{CE} / 75 \% \mathrm{CM}(0 \mathrm{~h})$ & 12,90 & 7,98 & 8,65 & 48,35 & 30,91 & 4,78 \\
\hline $100 \% \mathrm{CE}(4 \mathrm{~h})$ & 24,84 & 6,27 & 7,00 & 59,78 & 34,01 & 5,24 \\
\hline $75 \% \mathrm{CE} / 25 \% \mathrm{CM}(4 \mathrm{~h})$ & 21,94 & 6,20 & 7,03 & 59,76 & 33,51 & 5,95 \\
\hline $50 \% \mathrm{CE} / 50 \% \mathrm{CM}(4 \mathrm{~h})$ & 17,64 & 5,77 & 8,01 & 56,44 & 30,07 & 5,78 \\
\hline $100 \% \mathrm{CE} / 75 \% \mathrm{CM}(4 \mathrm{~h})$ & 14,42 & 8,20 & 8,74 & 49,76 & 30,68 & 6,13 \\
\hline $100 \% \mathrm{CE}(6 \mathrm{~h})$ & 22,70 & 6,22 & 7,28 & 61,61 & 31,41 & 5,96 \\
\hline $75 \% \mathrm{CE} / 25 \% \mathrm{CM}(6 \mathrm{~h})$ & 19,91 & 6,43 & 7,45 & 58,00 & 33,47 & 5,05 \\
\hline $50 \% \mathrm{CE} / 50 \% \mathrm{CM}(6 \mathrm{~h})$ & 17,08 & 7,18 & 7,65 & 53,68 & 31,43 & 4,33 \\
\hline $25 \% \mathrm{CE} / 75 \% \mathrm{CM}(6 \mathrm{~h})$ & 13,90 & 8,75 & 8,81 & 49,06 & 30,06 & 4,48 \\
\hline $100 \% \mathrm{CE}(8 \mathrm{~h})$ & 22,62 & 6,07 & 7,20 & 61,97 & 35,85 & 5,82 \\
\hline $75 \% \mathrm{CE} / 25 \% \mathrm{CM}(8 \mathrm{~h})$ & 19,30 & 6,89 & 7,62 & 56,14 & 30,21 & 3,27 \\
\hline $50 \% \mathrm{CE} / 50 \% \mathrm{CM}(8 \mathrm{~h})$ & 16,85 & 8,11 & 8,02 & 54,06 & 30,06 & 3,48 \\
\hline $25 \% \mathrm{CE} / 75 \% \mathrm{CM}(8 \mathrm{~h})$ & 13,55 & 8,11 & 9,19 & 48,88 & 29,59 & 4,37 \\
\hline $100 \% \mathrm{CM}$ & 10,50 & 8,98 & 10,00 & 41,63 & 28,46 & 4,26 \\
\hline
\end{tabular}

Capim-elefante (CE), casca de maracujá (CM), matéria seca (MS), matéria mineral (MM), extrato etéreo (EE), proteína bruta $(\mathrm{PB})$, fibra em detergente neutro $(\mathrm{FDN})$, fibra em detergente ácido (FDA), lignina (LIG), nitrogênio insolúvel em detergente ácido (NIDA), nitrogênio insolúvel em detergente neutro (NIDN), carboidratos totais (CHOT), carboidratos não fibrosos (CNF).

Os percentuais de matéria seca (MS), matéria mineral $(\mathrm{MM})$, extrato etéreo (EE), proteína bruta $(\mathrm{PB})$, fibra em detergente neutro (FDN), fibra em detergente ácido (FDA), lignina, nitrogênio insolúvel em detergente neutro (NIDN) e nitrogênio insolúvel em detergente ácido (NIDA) foram obtidos conforme metodologia descrita por Silva e Queiroz (2002). A FDN e a FDA foram determinadas utilizandose autoclave, no qual as amostras foram submetidas a uma pressão de $0,5 \mathrm{~atm}$ por 40 minutos.

Para o cálculo de carboidratos totais (CHOT), aplicou-se a equação CHOT $=100-(\mathrm{PB} \%+$ $\mathrm{EE} \%+\mathrm{MM} \%$ ) descrita por Sniffen et al. (1992). Os carboidratos não fibrosos (CNF) foram estimados pela equação $\mathrm{CNF}=100-(\mathrm{PB} \%+$ $\mathrm{FDN} \%+\mathrm{EE} \%+\mathrm{MM} \%$ ).

O delineamento experimental foi inteiramente ao acaso, em um esquema de parcela subdividida, com três repetições, sendo as parcelas constituídas por cinco níveis de inclusão de casca de maracujá $(0 ; 25 ; 50 ; 75$ e 100\%), e as subparcelas por quatro períodos de emurchecimento (zero, quatro, seis e oito horas). Utilizou-se, para as análises de variância, o

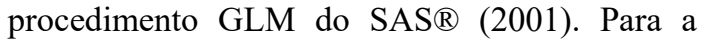
comparação das médias dos tratamentos, foi empregado o teste de Tukey a 5\% de probabilidade.

\section{RESULTADOS E DISCUSSÃO}

A avaliação sensorial classificou as silagens de todos os tratamentos como boa, uma vez que elas apresentaram coloração amarelada, odor levemente acre e ausência visível de bolor. Os tratamentos contendo casca de maracujá exalavam odor que lembrava o do fruto in natura. Uma repetição do tratamento $50 \% \mathrm{CE} / 50 \%$ CM e oito horas de emurchecimento apodreceu, devido ao rompimento da tampa do silo, e foi descartada, tendo sido analisada somente duas repetições desse tratamento.

A análise da variância mostrou que a concentração de maracujá e o tempo de 
emurchecimento do CE afetam as características fermentativas e a composição bromatológica das silagens. A influência de cada fator sobre os resultados obtidos foi discutida observando-se o desdobramento da interação, uma vez que foi observada interação significativa para a maioria das variáveis estudadas. $\mathrm{Na}$ Tab. 2, estão apresentados os resultados da comparação de médias das características fermentativas das silagens pelo teste Tukey a 5\% de probabilidade.
Os valores de $\mathrm{pH}$ das silagens foram influenciados pela inclusão da CM, variando de 3,58 para o tratamento com $100 \%$ de capimelefante com quatro horas de emurchecimento a 4,63 , para o tratamento $50 \% \mathrm{CE} / 50 \% \mathrm{CM}$ com oito horas de emurchecimento. As silagens compostas por misturas de CM e CE sem emurchecimento apresentaram $\mathrm{pH}$ acima de 4,0. $\mathrm{O}$ tempo de emurchecimento não influenciou o pH das silagens 100\% CE (Tab. 2).

Tabela 2. Valores médios de $\mathrm{pH}, \mathrm{N}-\mathrm{NH}_{3}$ e perdas totais das silagens de capim-elefante submetidas a diferentes tempos de emurchecimento e à inclusão de casca de maracujá in natura

\begin{tabular}{|c|c|c|c|c|c|c|c|}
\hline \multirow{2}{*}{$\begin{array}{c}\text { Tempo de } \\
\text { emurchecimento } \\
\text { (h) }\end{array}$} & \multicolumn{4}{|c|}{ Tratamentos } & \multirow[b]{2}{*}{$\begin{array}{c}100 \% \\
\mathrm{CM}\end{array}$} & \multirow[b]{2}{*}{$\begin{array}{l}\text { CV\% } \\
\text { Parcela }\end{array}$} & \multirow[b]{2}{*}{$\begin{array}{c}\text { CV\% } \\
\text { Subparcela }\end{array}$} \\
\hline & $100 \% \mathrm{CE}$ & $\begin{array}{c}75 \% \mathrm{CE} \\
25 \% \mathrm{CM} \\
\end{array}$ & $\begin{array}{c}50 \% \mathrm{CE} \\
50 \% \mathrm{CM} \\
\end{array}$ & $\begin{array}{l}25 \% \mathrm{CE} \\
75 \% \mathrm{CM} \\
\end{array}$ & & & \\
\hline \multicolumn{6}{|c|}{$\mathrm{pH}$} & 3,85 & 2,95 \\
\hline 0 & $3,77 \mathrm{Ba}$ & $4,23 \mathrm{Aa}$ & $4,25 \mathrm{Ab}$ & $4,18 \mathrm{Ab}$ & $3,74 \mathrm{Ba}$ & & \\
\hline 4 & $3,58 \mathrm{Ba}$ & $3,84 \mathrm{ABb}$ & $4,01 \mathrm{Ab}$ & $4,13 \mathrm{Ac}$ & $3,74 \mathrm{Ba}$ & & \\
\hline 6 & $3,69 \mathrm{Ca}$ & $3,84 \mathrm{BCb}$ & $4,17 \mathrm{ABb}$ & $4,35 \mathrm{Aa}$ & $3,73 \mathrm{Ca}$ & & \\
\hline 8 & $3,63 \mathrm{Da}$ & $4,00 \mathrm{BCab}$ & $4,63 \mathrm{Aa}$ & $4,15 \mathrm{Bd}$ & $3,74 \mathrm{CDa}$ & & \\
\hline \multicolumn{6}{|c|}{ N-NH ${ }_{3}$ - nitrogênio amoniacal (\%) } & 8,56 & 3,33 \\
\hline 0 & $8,11 \mathrm{Ba}$ & $9,51 \mathrm{Ab}$ & $10,44 \mathrm{Ab}$ & $10,44 \mathrm{Ab}$ & $9,97 \mathrm{Ba}$ & & \\
\hline 4 & $8,49 \mathrm{Ba}$ & $10,77 \mathrm{Aa}$ & $10,97 \mathrm{Aa}$ & $10,44 \mathrm{Ab}$ & $9,97 \mathrm{Ba}$ & & \\
\hline 6 & $8,63 \mathrm{Ba}$ & $10,38 \mathrm{Aab}$ & $11,38 \mathrm{Aa}$ & $11,65 \mathrm{Aab}$ & $9,97 \mathrm{Ba}$ & & \\
\hline 8 & $9,33 \mathrm{Ba}$ & $11,02 \mathrm{Aba}$ & $11,98 \mathrm{Aa}$ & $12,13 \mathrm{Aa}$ & $9,97 \mathrm{Ba}$ & & \\
\hline \multicolumn{6}{|c|}{ Perdas totais $(\mathrm{kg})$} & 35,47 & 6,4 \\
\hline 0 & $0,08 \mathrm{Da}$ & $0,28 \mathrm{Da}$ & $1,46 \mathrm{Cb}$ & $2,85 \mathrm{Aa}$ & $2,52 \mathrm{Ba}$ & & \\
\hline 4 & $0,10 \mathrm{Da}$ & $0,09 \mathrm{Da}$ & $0,37 \mathrm{Cc}$ & $1,59 \mathrm{Bb}$ & $2,52 \mathrm{Aa}$ & & \\
\hline 6 & $0,09 \mathrm{Ca}$ & $0,10 \mathrm{Ca}$ & $0,28 \mathrm{Cc}$ & $0,88 \mathrm{Bc}$ & $2,52 \mathrm{Aa}$ & & \\
\hline 8 & $0,10 \mathrm{Ca}$ & $0,13 \mathrm{Ca}$ & $1,92 \mathrm{Ba}$ & $1,75 \mathrm{Bb}$ & $2,52 \mathrm{Aa}$ & & \\
\hline
\end{tabular}

Capim-elefante (CE), casca de maracujá (CM); CV: coeficiente de variação da média; parcela: percentual de casca de maracujá, subparcela: tempo de emurchecimento. Médias seguidas de letras maiúsculas diferentes na mesma linha diferem entre si; médias seguidas de letras minúsculas diferentes na mesma coluna diferem entre si pelo teste de Tukey a $5 \%$ de probabilidade.

Segundo Mcdonald (1981), silagens de boa qualidade apresentam $\mathrm{pH}$ variando entre $3,8 \mathrm{e}$ 4,2. Os valores de $\mathrm{pH}$ relatados neste estudo encontram-se dentro da faixa proposta; com exceção das silagens com $50 \% \mathrm{CE} / 50 \% \mathrm{CM}$ e oito horas de emurchecimento e $25 \% \mathrm{CE}$ $75 \% / \mathrm{CM}$ e seis horas de emurchecimento $(4,63 \mathrm{e}$ 4,35 , respectivamente).

A inclusão do resíduo de maracujá e o tempo de emurchecimento do capim influenciaram a concentração de nitrogênio amoniacal $\left(\mathrm{N}-\mathrm{NH}_{3}\right)$ nas silagens (Tab. 2). As silagens de capimelefante com adição de $25 ; 50$ e $75 \%$ de $\mathrm{CM}$ apresentaram maiores médias de $\mathrm{N}-\mathrm{NH}_{3}$ em relação às silagens que não receberam o subproduto, independentemente do tempo de emurchecimento. Nas silagens com 50\% $\mathrm{CE} / 50 \% \mathrm{CM}$, o tempo zero diferiu dos demais tratamentos, apresentando menor concentração de $\mathrm{N}-\mathrm{NH}_{3}$.

$\mathrm{O} \quad \mathrm{N}-\mathrm{NH}_{3}$ das silagens variou entre $8,11 \mathrm{e}$ $12,13 \%$, ficando dentro do recomendado por Mcdonald et al. (1991). Os teores em N-NH sinalizam perdas de nitrogênio e, segundo os autores, não devem ultrapassar $12 \% \mathrm{~N}-\mathrm{NH}_{3}$ para obtenção de silagem de boa qualidade.

Com base em Mcdonald (1981), os teores de $\mathrm{pH}$ e N-NH${ }_{3}$ encontrados neste trabalho confirmam a ausência de fermentação secundária resultante da ação das bactérias do gênero Clostridium, que, em meio favorável ao seu desenvolvimento, conduzem ao desdobramento de aminoácidos, com produção de ácido butírico, ácidos voláteis, aminas, amônia e gases, prejudicando o valor nutritivo da silagem. 
Conforme apresentado na Tab. 2, a inclusão de $\mathrm{CM}$ elevou as perdas totais das silagens. As maiores perdas ocorreram nas silagens produzidas exclusivamente com casca de maracujá. $\mathrm{O}$ tempo de emurchecimento não influenciou as perdas totais das silagens com $100 \%$ de capim-elefante e com $75 \%$ CE $25 \% \mathrm{CM}$.

A elevação das perdas totais das silagens com a inclusão da CM deve-se ao alto teor de umidade presente na $\mathrm{CM}$ in natura $(89,5 \%)$. O aumento das perdas de líquidos e efluentes é característica de silagens com alta umidade e influencia as perdas totais durante a ensilagem.
Os teores de MS das silagens reduziram com a inclusão da casca de maracujá in natura (Tab. 3).

A redução dos teores de MS das silagens com a inclusão da casca de maracujá (CM) foi acarretada pelos baixos níveis de MS do aditivo, que, utilizado na forma in natura, apresentou teor de umidade inferior ao do capim-elefante (CE) $(10,50 \%$ e $21,01 \%$, respectivamente). Bonfá et al. (2015) também relataram diminuição no teor de MS à medida que a casca foi adicionada, o que evidencia que quanto maior o nível de inclusão da CM, maior o teor de umidade adicionado ao material.

Tabela 3. Teores de matéria seca, proteína bruta e extrato etéreo de silagens de capim-elefante submetidas a diferentes tempos de emurchecimento e à inclusão de casca de maracujá in natura

\begin{tabular}{|c|c|c|c|c|c|c|c|}
\hline \multirow{2}{*}{$\begin{array}{c}\text { Tempo de } \\
\text { emurchecimento } \\
(\mathrm{h})\end{array}$} & \multicolumn{5}{|c|}{ Tratamentos } & \multirow{2}{*}{$\begin{array}{l}\text { CV\% } \\
\text { Parcela }\end{array}$} & \multirow{2}{*}{$\begin{array}{l}\text { CV\% } \\
\text { Sub- } \\
\text { parcela }\end{array}$} \\
\hline & $100 \% \mathrm{CE}$ & $\begin{array}{l}75 \% \mathrm{CE} \\
25 \% \mathrm{CM}\end{array}$ & $\begin{array}{l}50 \% \mathrm{CE} \\
50 \% \mathrm{CM}\end{array}$ & $\begin{array}{l}25 \% \mathrm{CE} \\
75 \% \mathrm{CM}\end{array}$ & $100 \% \mathrm{CM}$ & & \\
\hline & \multicolumn{5}{|c|}{ Matéria seca (\%) } & 2,42 & 1,63 \\
\hline 0 & $20,61 \mathrm{Ad}$ & $17,16 \mathrm{Bc}$ & $15,43 \mathrm{abC}$ & $12,46 \mathrm{aD}$ & $9,75 \mathrm{Ea}$ & & \\
\hline 4 & $23,90 \mathrm{Aa}$ & $20,15 \mathrm{Ba}$ & $15,92 \mathrm{aC}$ & $12,98 \mathrm{aD}$ & $9,75 \mathrm{Ea}$ & & \\
\hline 6 & $22,83 \mathrm{Ab}$ & $18,63 \mathrm{Bb}$ & $14,89 \mathrm{bC}$ & $12,73 \mathrm{aD}$ & $9,75 \mathrm{Ea}$ & & \\
\hline \multirow[t]{2}{*}{8} & $21,75 \mathrm{Ac}$ & $19,03 \mathrm{Bb}$ & $15,87 \mathrm{aC}$ & $12,89 \mathrm{aD}$ & $9,75 \mathrm{Ea}$ & & \\
\hline & \multicolumn{5}{|c|}{ Proteína bruta (\%) } & 3,87 & 1,24 \\
\hline 0 & $7,12 \mathrm{Dc}$ & $6,81 \mathrm{Dc}$ & $7,71 \mathrm{Cb}$ & $8,70 \mathrm{Bb}$ & $11,66 \mathrm{Aa}$ & & \\
\hline 4 & 7,49Eb & $8,07 \mathrm{Db}$ & $8,47 \mathrm{Ca}$ & $9,35 \mathrm{Ba}$ & $11,66 \mathrm{Aa}$ & & \\
\hline 6 & $7,87 \mathrm{Da}$ & $8,09 \mathrm{Db}$ & $8,58 \mathrm{Ca}$ & $9,35 \mathrm{Ba}$ & $11,66 \mathrm{Aa}$ & & \\
\hline \multirow[t]{2}{*}{8} & 7,77Dab & $8,54 \mathrm{Ca}$ & $8,51 \mathrm{Ca}$ & $9,50 \mathrm{Ba}$ & $11,66 \mathrm{Aa}$ & & \\
\hline & \multicolumn{5}{|c|}{ Extrato etéreo $(\%)$} & 16,03 & 3,34 \\
\hline 0 & $2,04 \mathrm{Aa}$ & $2,03 \mathrm{Aa}$ & 1,99Aa & $1,90 \mathrm{Aa}$ & $1,41 \mathrm{Ba}$ & & \\
\hline 4 & $2,20 \mathrm{Aa}$ & $2,01 \mathrm{Aa}$ & $2,20 \mathrm{ABa}$ & $1,65 \mathrm{ABa}$ & $1,41 \mathrm{Ba}$ & & \\
\hline 6 & $2,28 \mathrm{Aa}$ & $2,03 \mathrm{Aa}$ & $2,21 \mathrm{Aa}$ & $1,94 \mathrm{Aa}$ & $1,41 \mathrm{Ba}$ & & \\
\hline 8 & $2,22 \mathrm{Aa}$ & 2,44Aa & $2,19 \mathrm{ABa}$ & $1,54 \mathrm{BCa}$ & $1,41 \mathrm{Ca}$ & & \\
\hline
\end{tabular}

Capim-elefante (CE), casca de maracujá (CM); CV: coeficiente de variação da média; parcela: percentual de casca de maracujá, subparcela: tempo de emurchecimento. Médias seguidas de letras maiúsculas diferentes na mesma linha as diferem entre si; médias seguidas de letras minúsculas diferentes na mesma coluna diferem entre si pelo teste de Tukey a 5\% de probabilidade.

O acompanhamento do processo agroindustrial que leva à obtenção desse subproduto pode detectar formas de minimizar a quantidade de água contida nele, melhorando a qualidade do produto in natura e facilitando-lhe a secagem se esta for a opção escolhida.

Os tempos de emurchecimento aumentaram o teor de MS das silagens, caso se compare ao tratamento com o capim não emurchecido. Contudo, o maior teor de MS foi observado em silagens com quatro horas de emurchecimento. $\mathrm{O}$ processo de emurchecimento exige dias abertos e ensolarados para a confecção da silagem, o que pode ser um problema, uma vez que o momento ideal para o corte das forrageiras geralmente coincide com a época de chuvas. Mudanças climáticas que ocorreram ao longo do dia de preparação das silagens influenciaram a desidratação do capim e provavelmente foram responsáveis pela inconsistência dos resultados, indicando a imprevisibilidade dessa técnica para aumentar o teor de matéria seca de silagens.

Verificou-se que, mesmo sem terem ocorrido perdas expressivas de MS, se observado o material ensilado, o teor máximo de MS foi de $23,9 \%$, na silagem exclusiva de CE com quatro horas de emurchecimento. Esse valor é inferior ao mínimo (30 a $35 \%$ de $\mathrm{MS}$ ) predito para 
obtenção de uma silagem de boa qualidade (McDonald et al., 1991). Entretanto, segundo Cândido et al. (2002), o teor de MS não é o único fator determinante na qualidade da silagem. $O$ teor de carboidratos presente no material a ser ensilado pode favorecer a fermentação, resultando em silagens de qualidade.

$A$ adição da $\mathrm{CM}$ propiciou um efeito positivo sobre o teor de PB da silagem (Tab. 3), devido ao maior percentual desse nutriente na casca de maracujá, se comparado ao capim-elefante $(10,0 \%$ e $6,56 \%$, respectivamente). Com exceção da silagem com $25 \%$ de CM sem emurchecimento, todas as silagens apresentaram teor de PB acima de 7\%, percentual mínimo recomendado para um bom funcionamento ruminal (Van Soest, 1994). Pompeu et al. (2006), ao trabalharem com níveis crescentes de maracujá desidratado, verificaram acréscimo nos teores de $\mathrm{PB}$ à medida que se incluía a $\mathrm{CM}$ desidratada.

O teor de PB das silagens com o capim-elefante emurchecido aumentou significativamente. Em geral, ocorreu um ganho de PB na silagem, caso se compare ao material ensilado, indicando que não houve perdas expressivas de $\mathrm{PB}$, o que seria esperado em ensilagem de material com alto teor de umidade. Ferrari Jr. e Lavezzo (2001) afirmaram que o excesso de umidade pode propiciar condições para obtenção de silagens butíricas, na quais é grande a decomposição proteica, com evidente queda no valor nutritivo do material original. A boa compactação dos silos e a presença de carboidratos solúveis no meio, possivelmente, proporcionaram boas condições fermentativas.

Os teores de EE decresceram com a inclusão da $\mathrm{CM}$ nas silagens, possivelmente pelo fato de o capim-elefante apresentar teor superior desse nutriente, quando comparado com a CM. O tempo de emurchecimento não influenciou os teores de extrato etéreo que, em geral, foram considerados baixos.

Observou-se uma redução nos níveis de FDN com a adição de CM nas silagens, principalmente nas silagens em que esse ingrediente chegou ao nível de 100\% (Tab. 4). Provavelmente o baixo nível de FDN da CM in natura em relação ao capim-elefante contribuiu para esse resultado.
Bonfá et al. (2015) relataram comportamento linear decrescente das concentrações em FDN à medida que se aumentaram os níveis da CM na silagem. Reis et al. (2000) observaram que a adição da CM na silagem de CE aumenta linearmente a digestibilidade aparente da FDN, fato que pode propiciar uma maior taxa de passagem, estimulando o consumo.

Assim como o FDN, os teores de FDA das silagens foram afetados pelos níveis de inclusão da CM. O menor valor de FDA foi encontrado na silagem com $100 \%$ da CM $(34,07 \%)$. O tempo de emurchecimento influenciou os valores de FDA das silagens quando essas tinham até $50 \%$ de CE na sua composição, em que a desidratação do capim reduziu os valores de FDA. Valores reduzidos de FDA são desejáveis porque podem aumentar a energia digestível da silagem, uma vez que o FDA constitui a parte mais indigestível da fibra presente nos volumosos.

Os teores em lignina das silagens foram baixos e o maior valor encontrado foi de $9,20 \%$ no tratamento $50 \% \mathrm{CE} / 50 \% \mathrm{CM}$ no tempo de oito horas de emurchecimento (Tab. 4). Contudo, a inclusão da CM nas silagens elevou os teores de NIDA e NIDN, com as maiores médias encontradas nas silagens de casca de maracujá in natura (4,18 e 3,27\%, respectivamente). O tempo de emurchecimento do $\mathrm{CE}$ não interferiu nos teores de NIDA das silagens dos tratamentos $50 \%$ CE $/ 50 \%$ CM e 25\% CE 75\% CM (Tab. 4).

Segundo Van Soest e Mason (1991), a elevação do teor de NIDA não é desejável, pois o nitrogênio retido na FDA não é aproveitado pelos microrganismos ruminais.

À medida que a casca de maracujá foi incluída nas silagens, observou-se uma redução nas concentrações de carboidratos totais (CHOT), apresentando diferença estatística entre os tratamentos e com as maiores médias para as silagens que não continham o subproduto. $\mathrm{O}$ tempo de emurchecimento do capim-elefante também influenciou a concentração de carboidratos, em que os maiores teores foram encontrados para o tratamento sem emurchecimento. Com a adição da casca de maracujá às silagens, houve um aumento nos teores médios de CNF, com média de 34,71\% para as silagens com $100 \%$ de CM. 
Tabela 4. Teores de FDN, FDA, lignina, NIDA, NIDN, carboidratos totais e CNF de silagens de capimelefante submetidas a diferentes tempos de emurchecimento e à inclusão de casca de maracujá in natura

\begin{tabular}{|c|c|c|c|c|c|c|c|}
\hline \multirow{2}{*}{$\begin{array}{l}\text { Tempo de } \\
\text { emurchecimento } \\
\text { (h) }\end{array}$} & \multicolumn{5}{|c|}{ Tratamentos } & \multirow{2}{*}{$\begin{array}{l}\text { CV\% } \\
\text { Parcela }\end{array}$} & \multirow{2}{*}{$\begin{array}{c}\mathrm{CV} \% \\
\text { Sub- } \\
\text { parcela }\end{array}$} \\
\hline & $100 \% \mathrm{CE}$ & $\begin{array}{c}75 \% \mathrm{CE} \\
25 \% \mathrm{CM} \\
\end{array}$ & $\begin{array}{c}50 \% \mathrm{CE} \\
50 \% \mathrm{CM} \\
\end{array}$ & $\begin{array}{l}25 \% \mathrm{CE} \\
75 \% \mathrm{CM} \\
\end{array}$ & $100 \% \mathrm{CM}$ & & \\
\hline & \multicolumn{5}{|c|}{ FDN - fibra em detergente neutro (\%) } & 7,02 & 1,39 \\
\hline 0 & $61,89 \mathrm{BCa}$ & $66,54 \mathrm{Aa}$ & $62,68 \mathrm{Ba}$ & $59,60 \mathrm{Ca}$ & $46,74 \mathrm{Da}$ & & \\
\hline 4 & $64,17 \mathrm{Aa}$ & $63,22 \mathrm{Ab}$ & $61,90 \mathrm{Aa}$ & $58,00 \mathrm{Bab}$ & $46,74 \mathrm{Ca}$ & & \\
\hline 6 & $61,98 \mathrm{Aa}$ & $61,69 \mathrm{Ab}$ & $60,91 \mathrm{Aa}$ & $56,10 \mathrm{Bb}$ & $46,74 \mathrm{Ca}$ & & \\
\hline \multirow[t]{2}{*}{8} & $62,82 \mathrm{Aa}$ & $62,60 \mathrm{Ab}$ & $60,30 \mathrm{Aa}$ & $57,19 \mathrm{Bba}$ & $46,74 \mathrm{Ca}$ & & \\
\hline & \multicolumn{5}{|c|}{ FDA - fibra em detergente ácido (\%) } & 5,85 & 2,00 \\
\hline 0 & $39,21 \mathrm{Ba}$ & $39,67 \mathrm{Ba}$ & $42,41 \mathrm{Aa}$ & $39,04 \mathrm{Ba}$ & $34,07 \mathrm{Ca}$ & & \\
\hline 4 & $37,53 \mathrm{Bab}$ & $39,59 \mathrm{ABa}$ & $40,32 \mathrm{Aa}$ & $38,23 \mathrm{ABa}$ & $34,07 \mathrm{Ca}$ & & \\
\hline 6 & $36,14 \mathrm{Bbc}$ & $36,97 \mathrm{Bb}$ & $37,06 \mathrm{Bb}$ & $37,61 \mathrm{Ba}$ & $34,07 \mathrm{Aa}$ & & \\
\hline \multirow[t]{2}{*}{8} & $36,65 \mathrm{Ac}$ & $37,33 \mathrm{Aab}$ & $38,36 \mathrm{Ab}$ & $38,37 \mathrm{Aa}$ & $34,07 \mathrm{Ba}$ & & \\
\hline & \multicolumn{5}{|c|}{ Lignina $(\%)$} & 15,57 & 7,08 \\
\hline 0 & $5,90 \mathrm{Aa}$ & $5,45 \mathrm{Ba}$ & $4,93 \mathrm{Bb}$ & 6,99Aa & $6,61 \mathrm{Aa}$ & & \\
\hline 4 & $4,82 \mathrm{Ba}$ & $3,61 \mathrm{Ba}$ & $5,44 \mathrm{ABb}$ & $5,39 \mathrm{ABb}$ & 6,61Aa & & \\
\hline 6 & $4,50 \mathrm{Ba}$ & $5,49 \mathrm{Ba}$ & $5,28 \mathrm{Bb}$ & $6,58 \mathrm{Aab}$ & 6,61Aa & & \\
\hline \multirow[t]{2}{*}{8} & $4,88 \mathrm{Ca}$ & $4,57 \mathrm{Ea}$ & $9,20 \mathrm{Aa}$ & $6,75 \mathrm{Ba}$ & $6,61 \mathrm{Da}$ & & \\
\hline & \multicolumn{5}{|c|}{ NIDA - nitrogênio insolúvel em detergente neutro (\%) } & 11,27 & 6,24 \\
\hline 0 & $1,56 \mathrm{Cb}$ & $2,26 \mathrm{BCb}$ & $2,61 \mathrm{Ba}$ & $2,62 \mathrm{Ba}$ & $4,18 \mathrm{Aa}$ & & \\
\hline 4 & $1,91 \mathrm{Cab}$ & $2,32 \mathrm{BCb}$ & $2,27 \mathrm{Ca}$ & $2,83 \mathrm{Ba}$ & $4,18 \mathrm{Aa}$ & & \\
\hline 6 & $2,36 \mathrm{Da}$ & $3,40 \mathrm{BCa}$ & $2,41 \mathrm{Da}$ & $2,87 \mathrm{CDa}$ & $4,18 \mathrm{Aa}$ & & \\
\hline \multirow[t]{2}{*}{8} & $1,93 \mathrm{Cab}$ & $2,20 \mathrm{BCb}$ & $2,34 \mathrm{BCa}$ & $2,66 \mathrm{Ba}$ & $4,18 \mathrm{Aa}$ & & \\
\hline & \multicolumn{5}{|c|}{ NIDN - nitrogênio insolúvel em detergente ácido (\%) } & 15,90 & 1,99 \\
\hline 0 & $1,77 \mathrm{Dc}$ & $1,95 \mathrm{Cb}$ & $1,93 \mathrm{Cb}$ & $2,24 \mathrm{Bb}$ & $3,27 \mathrm{Aa}$ & & \\
\hline 4 & $2,05 \mathrm{CDb}$ & $1,96 \mathrm{Db}$ & $2,11 \mathrm{Ca}$ & $2,47 \mathrm{Ba}$ & $3,27 \mathrm{Aa}$ & & \\
\hline 6 & $2,00 \mathrm{Cb}$ & $2,22 \mathrm{Ba}$ & $2,14 \mathrm{BCa}$ & $2,22 \mathrm{Bb}$ & $3,27 \mathrm{Aa}$ & & \\
\hline 8 & $2,22 \mathrm{Ca}$ & $2,14 \mathrm{Ca}$ & $2,25 \mathrm{Ca}$ & $2,60 \mathrm{Ba}$ & $3,27 \mathrm{Aa}$ & & \\
\hline \multicolumn{6}{|c|}{ CHOT - carboidratos totais $(\%)$} & 0,67 & 0,14 \\
\hline 0 & $84,04 \mathrm{Aa}$ & $83,80 \mathrm{Aa}$ & $82,66 \mathrm{Ba}$ & $80,33 \mathrm{Ca}$ & $77,30 \mathrm{D}$ & & \\
\hline 4 & $83,92 \mathrm{Aa}$ & $83,06 \mathrm{Bb}$ & $81,66 \mathrm{Cbc}$ & $80,14 \mathrm{Dab}$ & $77,30 \mathrm{E}$ & & \\
\hline 6 & $83,10 \mathrm{Abc}$ & $82,11 \mathrm{Bbc}$ & $81,42 \mathrm{Cc}$ & $79,66 \mathrm{Dbc}$ & $77,30 \mathrm{E}$ & & \\
\hline 8 & $83,19 \mathrm{Ac}$ & $82,80 \mathrm{Bc}$ & $79,39 \mathrm{Dd}$ & $79,91 \mathrm{Cc}$ & $77,30 \mathrm{E}$ & & \\
\hline \multicolumn{6}{|c|}{ CNF - carboidratos não fibrosos (\%) } & 17,17 & 4,51 \\
\hline 0 & $22,24 \mathrm{Ba}$ & $18,50 \mathrm{Ca}$ & $20,08 \mathrm{BCa}$ & $21,26 \mathrm{BCa}$ & $30,71 \mathrm{~A}$ & & \\
\hline 4 & $19,83 \mathrm{Ba}$ & $19,92 \mathrm{Ba}$ & $19,18 \mathrm{Ba}$ & $20,32 \mathrm{Ba}$ & $30,71 \mathrm{~A}$ & & \\
\hline 6 & $21,20 \mathrm{Ba}$ & $20,52 \mathrm{Ba}$ & $20,62 \mathrm{Ba}$ & $23,17 \mathrm{Ba}$ & $30,71 \mathrm{~A}$ & & \\
\hline 8 & $20,65 \mathrm{Ba}$ & $19,70 \mathrm{Ba}$ & $19,01 \mathrm{Ba}$ & $21,43 \mathrm{Ba}$ & $30,71 \mathrm{~A}$ & & \\
\hline
\end{tabular}

Capim-elefante (CE), casca de maracujá (CM); CV: coeficiente de variação da média; parcela: percentual de casca de maracujá, subparcela: tempo de emurchecimento. Médias seguidas de letras maiúsculas diferentes na mesma linha diferem entre si; médias seguidas de letras minúsculas diferentes na mesma coluna diferem entre si pelo teste de Tukey a $5 \%$ de probabilidade.

Cruz et al. (2010), ao avaliarem a inclusão de $0 \% ; 10 \% ; 20 \%$ e $30 \%$ de casca de maracujá desidratada na silagem de CE, também relataram um efeito linear decrescente nos teores de CHOT e um efeito linear crescente para a concentração de CNF com a inclusão da CM. O aumento no teor de CNF pode ser ocasionado pela elevada quantidade de pectina encontrada na casca de maracujá, que, de acordo com Lousada Júnior et al. (2006), pode chegar a $24,98 \%$.

\section{CONCLUSÕES}

Todos os tratamentos proporcionaram silagens com características sensoriais, fermentativas e bromatológicas que as classificam como de boa qualidade, destacando-se o tratamento com $75 \%$ de capim-elefante emurchecido durante quatro horas e $25 \%$ de casca de maracujá. O emurchecimento, de forma isolada, não aumenta os teores de matéria seca do capim-elefante em níveis desejáveis para uma boa silagem, necessitando de aditivos para melhorar a 
qualidade e a fermentação. A utilização da casca de maracujá in natura como aditivo ou como componente principal de silagens é possível, contudo a pré-secagem ou desidratação do material antes da ensilagem é preferível, a fim de reduzir as perdas por efluentes e melhorar o teor em MS da silagem.

\section{AGRADECIMENTOS}

À Fapeal e à Capes, pelo financiamento da pesquisa.

\section{REFERÊNCIAS}

BOLSEN, K.K.; LIN, B.E.; BRENT, B.E. et al. Effect of silage additives on the microbial succession and fermentation process of alfalfa and corn silage. $J$. Dairy Sci., v.75, p.3066-3083, 1992.

BONFÁ, C.S.; CASTRO, G.H.F.; VILLELA, S.D.J. et al. Silagem de capim-elefante adicionada de casca de maracujá. Arq. Bras. Med. Vet. Zootec., v.67, p.801808, 2015.

CÂNDIDO, M.J.D.; OBEID, J.A.; PEREIRA, O.G. et al. Características fermentativas e potencial biológico de silagens de híbridos de sorgo cultivados com doses crescentes de adubação. Rev. Ceres, v.49, p.151-167, 2002.

CRUZ, B.C.C.; SANTOS-CRUZ, C.L.; PIRES, A.J.V. et al. Composição bromatológica da silagem de capim-elefante com diferentes proporções de casca desidratada de maracujá (Passiflora edulis Sims $f$. flavicarpa). Rev. Bras. Cienc. Agrar., v.5, p.434-440, 2010.

FERRARI JÚNIOR, E.; LAVEZZO, W. Qualidade da silagem de capim-elefante (Pennisetum purpureum Schum.) emurchecido ou acrescido de farelo de Mandioca. Rev. Bras. Zootec., v.30, p.1424-1431, 2001.

FERREIRA, A.C.H.; NEIVA, J.N.M.; RODRIGUEZ, N.M. et al. Consumo e digestibilidade de silagens de capim-elefante com diferentes níveis de subproduto da agroindústria da acerola. Rev. Cienc. Agron., v.41, p.693-701, 2010.

FERREIRA. A.C.H.; NEIVA, J.N.M.; RODRIGUEZ, N.M. et al. Avaliação nutricional do subproduto da agroindústria de abacaxi como aditivo de silagem de capim-elefante. Rev. Bras. Zootec., v.38, p.223-229, 2009.

GONÇALVES, J.S.; NEIVA, J.N.M.; VIEIRA, N.F. et al. Valor nutritivo de silagens de capim elefante (Pennisetum purpureum Schum.) com adição de diferentes níveis dos subprodutos do processamento de acerola (Malpighia glabra L.) e de goiaba (Psidium guajava L.). Rev. Cienc. Agron., v.35, p.131-137, 2004.
HUSSBAUM, A.H.; WEISSBACH, B.F.; ELSÄSSER, A.M. et al. Grobfutterbewertung: Teil A - DLG-Schlüssel zur bewertung von grünfutter, silage und heu mit hilfe der sinnenprüfung. DLG Information. 2004. Available in: $<$ http://www.ensilagem.com.br/wpcontent/uploads/20 13/04/GROBFUTTERBEWERTUNG-II.pdf $>$. Accessed in: 5 Mar. 2017.

LOUSADA JÚNIOR, J.E.; COSTA, J.M.C.; NEIVA, J.N.M. et al. Caracterização físico-química de subprodutos obtidos do processamento de frutas tropicais visando seu aproveitamento na alimentação animal. Rev. Cienc. Agron., v.37, p.70-76, 2006.

McDONALD, P. The biochemistry of silage. Chichester: John Wiley \& Sons, 1981. p.218.

McDONALD, P.; HENDERSON, A.R.; HERON, S.J.E. The biochemistry of silage. 2.ed. Marlow: Chalcomb Publications, 1991. p.340.

POMPEU, R.C.F.F.; NEIVA, J.N.M.; CÂNDIDO, M.J.D. et al. Valor nutritivo de silagens de capimelefante (Pennisetum purpureum Schum) com adição de subprodutos do processamento de frutas tropicais. Rev. Cienc. Agron., v.37, p.77-83, 2006.

REIS, J.; PAIVA, P.C.A.; REZENDE, C.A. et al. Composição química, consumo voluntário e digestibilidade de silagens de resíduos do fruto de maracujá (Passiflora edulis Sims f. flavicarpa) e de capim-elefante (Pennisetum purpureum Schum) cv. Cameroon e suas combinações. Cienc. Agrotec., v.24, p.213-224, 2000.

SÁ, C.R.; NEIVA, J.N.M.; GONÇALVES, J.S. et al. Composição bromatológica e características fermentativas de silagens de capim elefante (Pennisetum purpureum Schum.) com níveis crescentes de adição do subproduto da Manga (Mangifera indica L.). Rev. Cienc. Agron., v.38, p.199-203, 2007.

SAS user's guide: statistics. Cary: SAS, 2001.

SILVA, D.J.; QUEIROZ, A.C. Análise de alimento: métodos químicos e biológicos. 3.ed. Viçosa, MG: UFV, 2002. 235p.

SNIFFEN, C.J.; O'CONNOR, J.D.; VAN SOEST, P.J. et al. A net carbohydrate and protein system for evaluating cattle diets: 11 . Carbohydrate and protein availability. J. Anim. Sci., v.70, p.3562-3577, 1992.

VAN SOEST, P.J. Nutritional ecology of the ruminant. 2.ed. Ithaca: Cornell University Press, 1994. 476p.

VAN SOEST, P.J.; MASON, V.C. The influence of Maillard reaction upon the nutritive value of fibrous feeds. Anim. Feed Sci. Techn., v.32, p.45-53, 1991. 